\title{
Pharmacogenetics in the rheumatic diseases
}

\section{B N Cronstein}

Ann Rheum Dis 2004;63(Suppl II):ii25-ii27. doi: 10.1136/ard.2004.028217

O ne of the promises of the human genome project is individualised pharmacological therapy. An individual's genetic type would be determined, and the resulting diseases which the person was susceptible to would be determined. In addition, the drugs to which an individual would respond well would be enumerated, and the drugs which were more likely to be toxic could be established. At present we are just beginning to determine those associations which would help us tailor an individual's pharmacological therapy so as to maximise efficacy and minimise toxicity. In this report we review the considerations involved in determining the pharmacogenetic profile of any given drug and to review the current level of understanding of the association between genetic polymorphisms and drug toxicity/efficacy in rheumatology.

Establishing an association between genetic types and toxicity is perhaps an easier task to accomplish than understanding the association between a given genetic type and drug efficacy. Drug toxicities are generally discrete events and a specific toxicity can often be traced to the agent in question. Thus, it is fairly easy to study a given population and define those with a specific drug toxicity. Nonetheless, a sufficiently large population must be studied to establish an association. Although this restates the obvious, most drugs for chronic conditions such as rheumatoid arthritis (RA) are toxic to only a modest proportion of the patients taking them otherwise they would have long ago been pulled off the market. To establish a relative risk association for a toxicity that occurs in only $5-10 \%$ of patients taking a given drug might require hundreds or even thousands of patients if the observed increase in risk of toxicity is modest.

There are many reasons why any given drug may fail in any given individual. Clearly, genetically associated resistance may account for failure of a given agent and being able to predict drug failure can both prevent unnecessarily prolonged suffering as the drug is given "a chance to work" as well as diminishing the exposure of the patient to a potentially toxic reaction. Nonetheless other factors can also account for drug failure in the treatment of a chronic disease. First, as we have found recently for RA, patients with longstanding, severe disease may not respond to any therapy because the disease has progressed too far. Some patients suffer a more severe form of the disease even from the outset and the susceptibility to more severe disease may also be genetic in origin. The best example of a genetic determinant of more severe disease in the rheumatic diseases is the presence of the "shared epitope" in human leucocyte antigen (HLA) molecules in patients with RA who suffer a more severe course. ${ }^{1}$ Other drugs or even dietary substances may interfere with the action of a drug-for example, caffeine, an adenosine receptor antagonist present in coffee and other soft drinks, blocks the anti-inflammatory effects of methotrexate in animal studies and patients with RA. ${ }^{2-4}$ Thus, genetics may be only one contributing factor in the failure of a drug in the treatment of a chronic disease such as RA. Moreover, sorting out which patients fail drug therapy due to genetically based

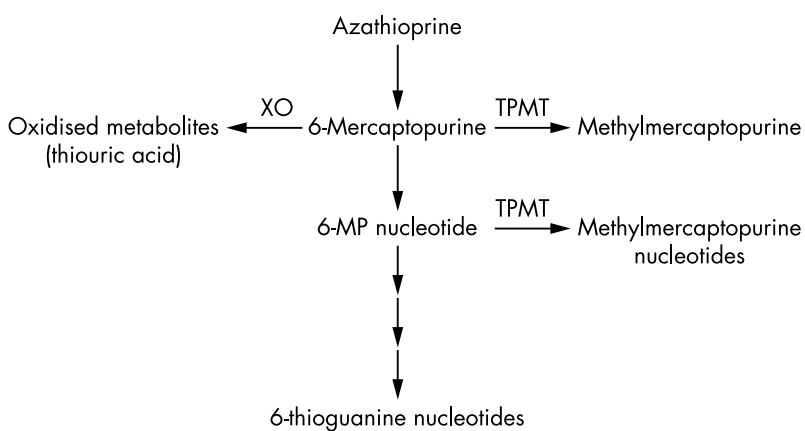

Figure 1 Metabolism of azathioprine. MP, mercaptopurine; TPMT, thiopurine methyl transferase; $X O$, xanthine oxidase.

resistance from those who fail because of other issues may not be possible in large series.

Azathioprine has long been used to treat systemic lupus erythematosus and severe manifestations of RA. Azathioprine is converted to 6-mercaptopurine in the liver, and 6-mercaptopurine can be further metabolised by xanthine oxidase or metabolised by thiopurine methyl transferase (TPMT) and the products excreted (fig 1). The therapeutic effects of the drug result from hypoxanthine phosphoribosyl transferase mediated conversion to 6-thioguanine nucleotides which are incorporated into DNA by proliferating cells with resulting cytotoxicity. It has been recognised for many years that accumulation of thiopurine metabolites is associated with severe marrow suppression and within the past few years both genetically determined alterations in enzyme activity and the genetic polymorphisms associated with diminished TPMT activity have been elucidated (reviewed in reference 5). In general $10-11 \%$ of most Caucasian populations are heterozygous for the wild-type gene and a common variant (G460A and A719G). Patients who are heterozygous for these polymorphisms are at increased risk of developing marrow toxicity although individuals who are homozygous for the variant allele are at risk of catastrophic marrow suppression by standard doses of azathioprine. Different genetic variants seem to occur with similar frequency in other ethnic and racial groups. Thus, susceptibility to severe marrow toxicity induced by standard doses of azathioprine can be predicted based on the genotype of the patient. Although use of azathioprine in the treatment of rheumatic diseases has diminished it remains a potent and effective agent in the right circumstances. Genotyping of individuals can be carried out so as to avoid inducing disastrous marrow toxicity in susceptible individuals.

Methotrexate is currently the most commonly used disease modifying antirheumatic drug (DMARD) in RA for which it is commonly administered alone or in combination with

Abbreviations: AICAR, aminoimidazolecarboxamidoribonucleotide; MTHFR, methylene tetrahydrofolate reductase; RA, rheumatoid arthritis; TPMT, thiopurine methyl transferase 


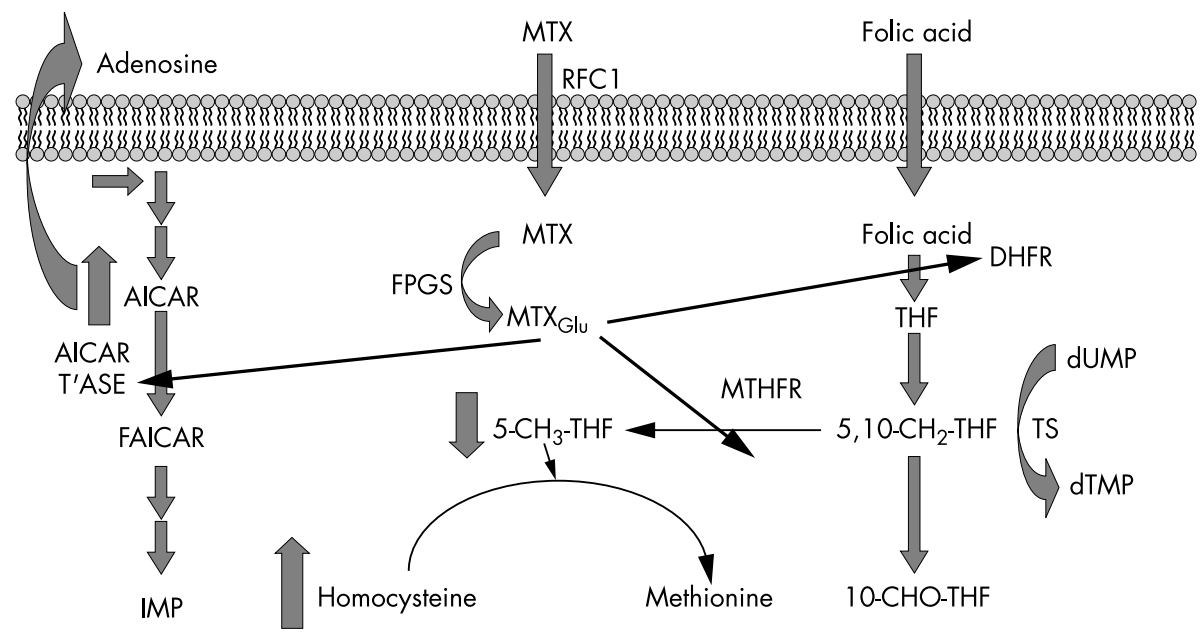

Figure 2 Methotrexate and cellular metabolism. 5- $\mathrm{CH}_{3}$-THF, 5-methyl-tetrahydrofolate; AICAR, aminoimidazolecarboxamidoribonucleotide; DHFR, dihydrofolate reductase; dTMP, deoxythymidine monophosphate; dUMP, deoxyutidine monophosphate; FAICAR, formyl aminoimidazolecarboxamidoribonucleotide; FPGS, folylpolyglutamate synthase; IMP, inosine monophosphate; MTHFR, methylene tetrahydrofolate reductase; MTX, methotrexate; $\mathrm{MTX}_{\mathrm{glu}}$, methotrexate polyglutamate; RFCl, reduced folate carrier 1; THF, tetrahydrofolate; TS, thymidylate synthase.

other small molecules or biologic agents. Methotrexate is an analogue of folic acid that is taken up by specific transporters into the cell where it interferes with the synthesis of purines and pyrimidines as well as blocking the conversion of homocysteine to methionine (fig 2). Once inside the cell methotrexate is polyglutamated which confers both longevity on the polyglutamated metabolites and alters the spectrum of enzymes inhibited by the drug; methotrexate polyglutamates inhibit aminoimidazolecarboxamidoribonucleotide (AICAR) transformylase, an enzyme involved in the de novo synthesis of purines, most potently. The inhibition of AICAR transformylase by methotrexate polyglutamates is associated with the accumulation of AICARiboside and increased release of adenosine which mediates many of the anti-inflammatory effects of methotrexate. ${ }^{6}$

Methylene tetrahydrofolate reductase (MTHFR) is a folate dependent enzyme that catalyses the conversion of homocysteine to methionine. Severe deficiency of MTHFR is associated with homocysteinaemia and homocysteinuria, neuropathy and encephalopathy, and coagulopathy and vasculopathy. Common variants in the enzyme are associated with a modest decrease in MTHFR activity; $40 \%$ of the population is heterozygous for the C677T polymorphism and $8-10 \%$ is homozygous for this polymorphism. Heterozygosity for the C677T polymorphism leads to a $30-40 \%$ reduction in enzyme activity and homozygosity is associated with a $70 \%$ reduction in activity. The Al298C polymorphism is in linkage disequilibrium with the C677T polymorphism so that 50$100 \%$ of those with the minority polymorphism at position 677 will also have the minority polymorphism at position 1298. Recent studies have elucidated the role of genetic polymorphisms in the enzyme involved in the conversion of homocysteine to methionine, MTHFR, in excess methotrexate marrow toxicity in patients with RA. $^{7-9}$ One of these studies reported that the A1298C polymorphism was also associated with diminished efficacy (defined as requiring $>10 \mathrm{mg} /$ week of methotrexate) although this was not confirmed in a subsequent study. ${ }^{78}$ Thus, the results of these studies demonstrate that the C677T polymorphism is associated with enhanced methotrexate mediated marrow toxicity.

Clearly a genetic test that predicted response to methotrexate would be greatly welcomed by the rheumatology community. In one recent study an additive effect on methotrexate efficacy was demonstrated for polymorphisms in thymidylate synthase (involved in folate dependent pyrimidine synthesis), AICAR transformylase and RFCl (the protein that transports methotrexate into the cell). ${ }^{10}$ Individuals with a polymorphism in more than one of these genes had a better response to methotrexate than those with none. This was a small study, however, and the role of these polymorphisms in methotrexate response requires further study.

\section{CONCLUSION}

It is now possible to predict which patients are susceptible to some forms of drug toxicity in the therapy of the rheumatic diseases. In particular, azathioprine toxicity can clearly be prevented by the avoidance of this drug in those patients who are incapable of eliminating its toxic metabolites. In patients treated with methotrexate the toxicities associated with genetic polymorphisms can also be prevented by avoiding the drug but most therapeutic series indicate that supplementation with either folate or folinic acid can prevent most of these toxicities as well. ${ }^{11-24}$ There is no complete evidence yet to indicate that we can predict which patients are most likely to respond to methotrexate, nonetheless efforts are continuing to determine if genetic polymorphisms in enzymes or proteins of methotrexate's anti-inflammatory pathways determine response to the drug. Although not in a position yet to fully take advantage of the insights gained in the past few years, future studies will likely bring the benefits of the genetic revolution to patients with rheumatic diseases.

This work was supported by grants from the National Institutes of Health (AA13336, AR41911, GM56268), Scleroderma Foundation, King Pharmaceuticals, the General Clinical Research Center (M01RR00096) and by the Kaplan Cancer Center of New York University School of Medicine.

Correspondence to: Professor B N Cronstein, New York University School of Medicine, 550 First Ave., New York, NY 10016; cronsb01@ med.nyu.edu

\section{REFERENCES}

1 Yen JH, Moore BE, Nakajima T, Scholl D, Schaid DJ, Weyand CM, et al. Major histocompatibility complex class I-recognizing receptors are disease risk genes in rheumatoid arthritis. J Exp Med 2001;193:1159-67.

2 Nesher G, Mates M, Zevin S. Effect of caffeine consumption on efficacy of methotrexate in rheumatoid arthritis. Arthritis Rheum 2003;48:571-2.

3 Montesinos MC, Yap JS, Desai A, Posadas I, McCrary CT, Cronstein BN. Reversal of the antiinflammatory effects of methotrexate by the nonselective adenosine receptor antagonists theophylline and caffeine. Evidence that the 
antiinflammatory effects of methotrexate are mediated via multiple adenosine receptors in rat adjuvant arthritis. Arthritis Rheum 2000;43:656-63.

4 Silke C, Murphy MS, Buckley T, Busteed S, Molloy MG, Phelan M. The effects of caffeine ingestion on the efficacy of methotrexate. Rheumatology (Oxford) 2001;40(suppl 1):34.

5 Clunie GP, Lennard L. Relevance of thiopurine methyltransferase status in rheumatology patients receiving azathioprine. Rheumatology (Oxford) 2004;43:13-18

6 Chan ES, Cronstein BN. Molecular action of methotrexate in inflammatory diseases. Arthritis Res 2002;4:266-73.

7 Kumagai K, Hiyama K, Oyama T, Maeda H, Kohno N. Polymorphisms in the thymidylate synthase and methylenetetrahydrofolate reductase genes and sensitivity to the low-dose methotrexate therapy in patients with rheumatoid arthritis. Int J Mol Med 2003;1 1:593-600.

8 Urano W, Taniguchi A, Yamanaka H, Tanaka E, Nakajima H, Matsuda Y, et al. Polymorphisms in the methylenetetrahydrofolate reductase gene were associated with both the efficacy and the toxicity of methotrexate used for the treatment of rheumatoid arthritis, as evidenced by single locus and haplotype analyses. Pharmacogenetics 2002;12:183-90.

9 van Ede AE, Laan RF, Blom HJ, Huizinga TW, Haagsma CJ, Giesendorf BA, et al. The C677T mutation in the methylenetetrahydrofolate reductase gene: genetic risk factor for methotrexate-related elevation of liver enzymes in rheumatoid arthritis patients. Arthritis Rheum 2001;44:2525-30.

10 Dervieux T, Lein DO, Park G, Barham R, Smith K, Walsh M, et al. Single nucleotide polymorphisms (SNPs) in the folate/purine pathway predict methotrexate's effects in rheumatoid arthritis. Arthrits Rheum 2003;48(suppl): 1093 .

11 Dijkmans BA. Folate supplementation and methotrexate. $\mathrm{Br} J$ Rheumatol 1995;34:1172-4.

12 Cooper BA. Folic acid and methotrexate in rheumatoid arthritis. Ann Intern Med 1996; 124(1 Pt 1):73; discussion 74.

13 Kavanaugh A, Kavanaugh D. Folic acid and methotrexate in rheumatoid arthritis. Ann Intern Med 1996:124(1 Pt 1):73; discussion 74

14 Shiroky JB. Folic acid and methotrexate in rheumatoid arthritis. Ann Intern Med 1996;124(1 Pt 1):73-4.
15 Shiroky JB. The use of folates concomitantly with low-dose pulse methotrexate. Rheum Dis Clin North Am 1997;23:969-80.

16 Hunt PG, Rose CD, Mcllvain-Simpson G, Tejani S. The effects of daily intake of folic acid on the efficacy of methotrexate therapy in children with juvenile rheumatoid arthritis. A controlled study. J Rheumatol 1997;24:2230-2.

17 Ortiz Z, Shea B, Suarez-Almazor ME, Moher D, Wells GA, Tugwell P. The efficacy of folic acid and folinic acid in reducing methotrexate gastrointestinal toxicity in rheumatoid arthritis. A metaanalysis of randomized controlled trials. J Rheumatol 1998;25:36-43.

18 Morgan SL, Baggott JE, Lee JY, Alarcon GS. Folic acid supplementation prevents deficient blood folate levels and hyperhomocysteinemia during longterm, low dose methotrexate therapy for rheumatoid arthritis: implications for cardiovascular disease prevention. J Rheumatol 1998;25:441-6.

19 Pincus T. Folic and folinic acid supplementation reduces methotrexate gastrointestinal side effects in rheumatoid arthritis. Clin Exp Rheumatol 1998; 16:667-8.

20 Ravelli A, Migliavacca D, Viola S, Ruperto N, Pistorio A, Martini A. Efficacy of folinic acid in reducing methotrexate toxicity in juvenile idiopathic arthritis. Clin Exp Rheumatol 1999;17:625-7.

21 Ortiz Z, Shea B, Suarez Almazor M, Moher D, Wells G, Tugwell P. Folic acid and folinic acid for reducing side effects in patients receiving methotrexate for rheumatoid arthritis. Cochrane Database Syst Rev 2000;2:CD000951.

22 van Ede $A E$, Laan RF, Rood MJ, Huizinga TW, van de Laar MA, van Denderen $\mathrm{CJ}$, et al. Effect of folic or folinic acid supplementation on the toxicity and efficacy of methotrexate in rheumatoid arthritis: a forty-eight week, multicenter, randomized, double-blind, placebo-controlled study. Arthritis Rheum 2001;44:1515-24.

23 Endresen GK, Husby G. Folate supplementation during methotrexate treatment of patients with rheumatoid arthritis. An update and proposals for guidelines. Scand J Rheumatol 2001;30:129-34.

24 Morgan SL, Baggott JE, Vaughn WH, Young PK, Austin JV, Krumdieck CL, et al. The effect of folic acid supplementation on the toxicity of low-dose methotrexate in patients with Rheumatoid Arthritis. Arthritis Rheum 1990;33:9-18. 